\title{
Immunostaining and Laser-Assisted Cell Picking for mRNA Analysis
}

\author{
Ludger Fink, Thomas Kinfe, Maria Magdalena Stein, Leander Ermert, Jörg Hänze, \\ Wolfgang Kummer, Werner Seeger, and Rainer Maria Bohle
}

Departments of Pathology (LF, TK, MMS, LE, RMB) and Internal Medicine (LF, JH, WS), and the Institute for Anatomy and Cell Biology (WK), Justus-Liebig-University, Giessen, Germany

SUMMARY: Isolation of single cells or cell clusters from complex tissue sections has become possible by microdissection techniques. Employing laser-assisted cell picking, cell-specific mRNA analysis of a few isolated cell profiles may be performed. However, microscopic discrimination of different cell types in routinely stained tissue sections is limited, whereas immunostaining enables a more precise access to cells of interest. This approach was noted to interfere with mRNA recovery. To define optimal conditions for mRNA amplification from immunodetected cells, we systematically investigated several potential affectors. Kind of fixation, antibodies and staining reagents, incubation and total processing time, and digestion with proteinase $\mathrm{K}$ turned out to influence mRNA stability. We present rapid protocols for immunohistochemistry and immunofluorescence with total incubation times of approximately 25 to 40 minutes and 10 to 20 minutes, respectively, and suggest mRNA amplification without a preceding extraction step. Applying these protocols to oligocellular clusters containing approximately 20 cell profiles and nuclei each from lung and kidney tissue, the highest efficiency rates of mRNA amplification were obtained when combining short-term formalin fixation, reduction of antibody incubation time, application of immunofluorescence, and digestion with proteinase $\mathrm{K}$. Thus, the successful combination of immunostaining and laser-assisted cell picking remarkably improves cell type-specific analysis of gene expression within complex tissues. (Lab Invest 2000, 80:327-333).

C ell-specific molecular analysis has attracted major interest in many fields of biomedical research. Microdissection techniques have been proven to be reliable tools for procuring defined parts of tissue (Emmert-Buck et al, 1997) or even a few cell profiles (Becker et al, 1997; Küppers et al, 1993) from stained tissue sections. Apart from DNA analysis, detection of mRNA after microdissection of tissue islets with several hundreds of cells was shown (Hiller et al, 1996; Ho et al, 1998). In particular, application of a ultraviolet laser-microdissection system was found to allow a successful mRNA investigation from a few cell profiles in formalin-fixed tissue (Schütze and Lahr, 1998) or cryosections (Hölschermann et al, 1999). Beyond qualitative mRNA analysis, this group recently demonstrated the detection of a special splicing variant in single cell profiles (Kummer et al, 1998) or cell types (Fink et al, 1999) after laser-assisted cell picking. Combination with real-time quantitative PCR even allowed a reliable mRNA quantitation from a few cell profiles (Fink et al, 1998).

Discrimination of cell types in a hematoxilin-stained frozen section is, however, limited, but immunohistochemical staining might provide access for more precise detection of single cell types or cells for selective

Received October 15, 1999.

This study was supported by the Deutsche Forschungsgemeinschaft (SFB 547 Cardiopulmonary vascular system, project Z1).

Address reprint requests to: Dr. Ludger Fink, Institut für Pathologie, Universität Gießen, Langhansstr. 10, D 35392 Gießen, Germany. Fax: 4964199 41109; E-mail: Ludger.Fink@patho.med.uni-giessen.de isolation. For DNA analysis, microdissection of single cells after immunostaining was performed in paraffinembedded archival tissue (d'Amore et al, 1997). In these investigations, semi-nested PCR was used and amplification was detectable in $35 \%$ of the harvested cells (average with significant case-to-case variation). Concerning mRNA amplification, this was reported to be undertaken in several hundred microdissected cells after immunostaining (Fend et al, 1999) as well as in single dispersed and immunostained, but intact cells (Jin et al, 1999).

Picking 10 to 15 cell profiles from hematoxilinstained cryosections, we obtained efficiency rates of mRNA amplification of $75 \%$ to $82 \%$ (Fink et al, 1998 , 1999). Although mRNA analysis from a few immunostained and microdissected cell profiles has not been reported yet, our pilot experiments forwarded a remarkably lower mRNA recovery in tissues undergoing conventional alkaline phosphatase and monoclonal anti-alkaline phosphatase (APAAP) immunostaining. Addressing the variables that might interfere with the efficiency of mRNA amplification in a systematic fashion, we adapted our rapid protocol of laser-assisted cell picking to immunostaining techniques to obtain optimal conditions for mRNA analysis.

\section{Results}

We investigated the effect of fixation, processing time, antibodies, and staining reagents as well as proteinase $\mathrm{K}(\mathrm{PK})$ digestion on mRNA stability and amplifiability. Overall, 513 samples with oligocellular clusters 
containing approximately 20 cell profiles and nuclei each were picked (Fig. 1, A to D). For amplification we selected mRNA encoding for the housekeeping gene version of porphobilinogen deaminase (PBGD), a ubiquitously, moderately, and consistently expressed gene (Fig. 2).

\section{Buffer Incubation Period}

First we tested the effect of the time span, for which tissue sections are positioned in liquid solutions, on mRNA recovery. To discriminate the additional influence of antibodies and reagents, we compared tissue sections that were immediately stained with hematoxilin with those stored in sterile Tris-buffered saline $\mathrm{pH}$ 7.5) in the absence of antibodies and reagents for 30 minutes before hematoxilin staining (see Fig. 3A). For cryosections of the lung, we found a picking efficiency (percentage of positive samples for PBGD mRNA) that corresponds well with previous reports of this group. Interestingly, a mild digestion with $\mathrm{PK}\left(53^{\circ} \mathrm{C}, 30\right.$ minutes) caused a further moderate increase in the efficiency rate $(83 \%+\mathrm{PK}$ vs $70 \%-\mathrm{PK})$. After 30 minutes storage in buffer, efficiency was markedly reduced to $50 \%(+\mathrm{PK})$ and $33 \%(-\mathrm{PK})$. In samples originating from lungs fixed by formalin perfusion for 15 minutes, a lower efficiency rate was found immediately after staining (55\% - PK), which even dropped upon 30 minutes buffer incubation (25\% -PK). Higher rates were obtained again by a digestion with $\mathrm{PK}, 65 \%$ after staining and $58 \%$ after 30 minutes buffer.

\section{Effect of Antibodies and Staining Reagents}

To assess the effect of antibodies and developing solution on RNA stability in general, pure copyRNA (cRNA) aliquots of a cloned PBGD PCR-product were incubated at room temperature adding the anti-monocyte/macrophage ED-1 antibody, at time points and in concentrations comparable to tissue application (30 minutes; 1:12.5). Alternatively, developing solution was additionally applied (30 minutes). RNase inhibitor (400 U/ml) was optionally added to both approaches. RNA was quantified by real-time RT-PCR after an extraction step (Table 1). When compared with RNA that was only extracted, all reagents resulted in a significant loss $(p<0.001)$. Determined by $\Delta \mathrm{C}_{\mathrm{T}}$ method, incubation with the antibody (to mimic immunofluorescence staining) reduced the cRNA amount to $48 \% \pm 16 \%$ ( - RNase inhibitor) and 54\% $\pm 14 \%(+$ RNase inhibitor). Application of developing solution (to mimic immunochemical staining) led to a further significant decrease of cRNA amount $(p=0.04)$ to $27 \%$ $\pm 10 \%$ (- RNase inhibitor) and 25\% $\pm 8 \%$ ( + RNase inhibitor). Incubation with RNase inhibitor did not affect the loss significantly.

Next we tested the effect of antibodies and reagents for APAAP staining within tissue sections. Depending on the binding affinities of the different antibodies, incubation times were reduced. Thus, the overall APAAP protocol lasted approximately 25 to 40 minutes. Examples of staining are given in Figure 1, $A$ and
F. Applying immunostaining to cryosections of lung tissue, PBGD mRNA was detected in $25 \%$ without PK, and in 36\% with PK digestion (Fig. 3B). An identical staining procedure to cryosections of the lung initially fixed by perfusion with formalin resulted in $20 \%$ (-PK) and $37 \%(+P K)$. Similar rates were obtained after fixation by 2 - to 6 -hour immersion in formalin. Performing immunofluorescence, the overall staining protocols lasted approximately 10 to 20 minutes (examples of staining are given in Fig. 1, E and G). As shown in Figure 3C, efficiency rates for mRNA amplification in lung cryosections were $40 \%(+\mathrm{PK})$ and $20 \%(-\mathrm{PK})$, in formalin-fixed lung tissue $49 \%$ and $46 \%$ (+PK), without PK digestion 17\%. When compared with APAAP staining results, the immunofluorescence protocol was able to improve the recovery significantly ( $p=$ 0.04). Application of an RNase inhibitor did not affect efficiency rates when added to the antibodies during the incubation periods, neither for APAAP staining nor for immunofluorescence staining (data not shown).

\section{Effect of Tissue Structure}

When investigating samples from cryo- and formalinfixed kidneys, efficiency rates of mRNA amplification were in the same range as obtained from lung tissue, again with higher RNA recovery in the presence of PK (Fig. 3, B and C).

\section{PK Digestion}

Comparing PK-treated samples with non-treated samples in total, the application of a digestion step improved the results significantly ( $p<0.001$ ).

\section{Discussion}

Isolation of single cell profiles or oligocellular clusters allows a cell-specific or cell type-specific analysis of mRNA expression in complex tissues. As many cell types cannot be precisely identified after routine staining, immunostaining is often a precondition to obtain the cell profiles of interest. However, this approach is hampered by the effect of staining procedure on the RNA stability.

Addressing this issue in a systematic manner, we analyzed mRNA from oligocellular clusters. After different immunological staining procedures, these samples were picked from lung tissue (alveolar septum cells and macrophages) or kidney tissue (renal glomerulus cells), respectively. The following variables were found to influence the RNA recovery from these cell clusters:

Buffer Incubation Period. Incubation in buffer fluid per se resulted in a marked drop in the efficiency rate of mRNA amplification. Endogenous RNases, as well as RNA loss due to "elution" into the surrounding bulk of buffer fluid, offer the most plausible explanations for this rapid loss of RNA recovery.

Fixation Technique. Compared with cryosections, formalin fixation-whether performed by perfusion or by immersion of the tissue-resulted in a lower percentage of positive samples when the samples were 

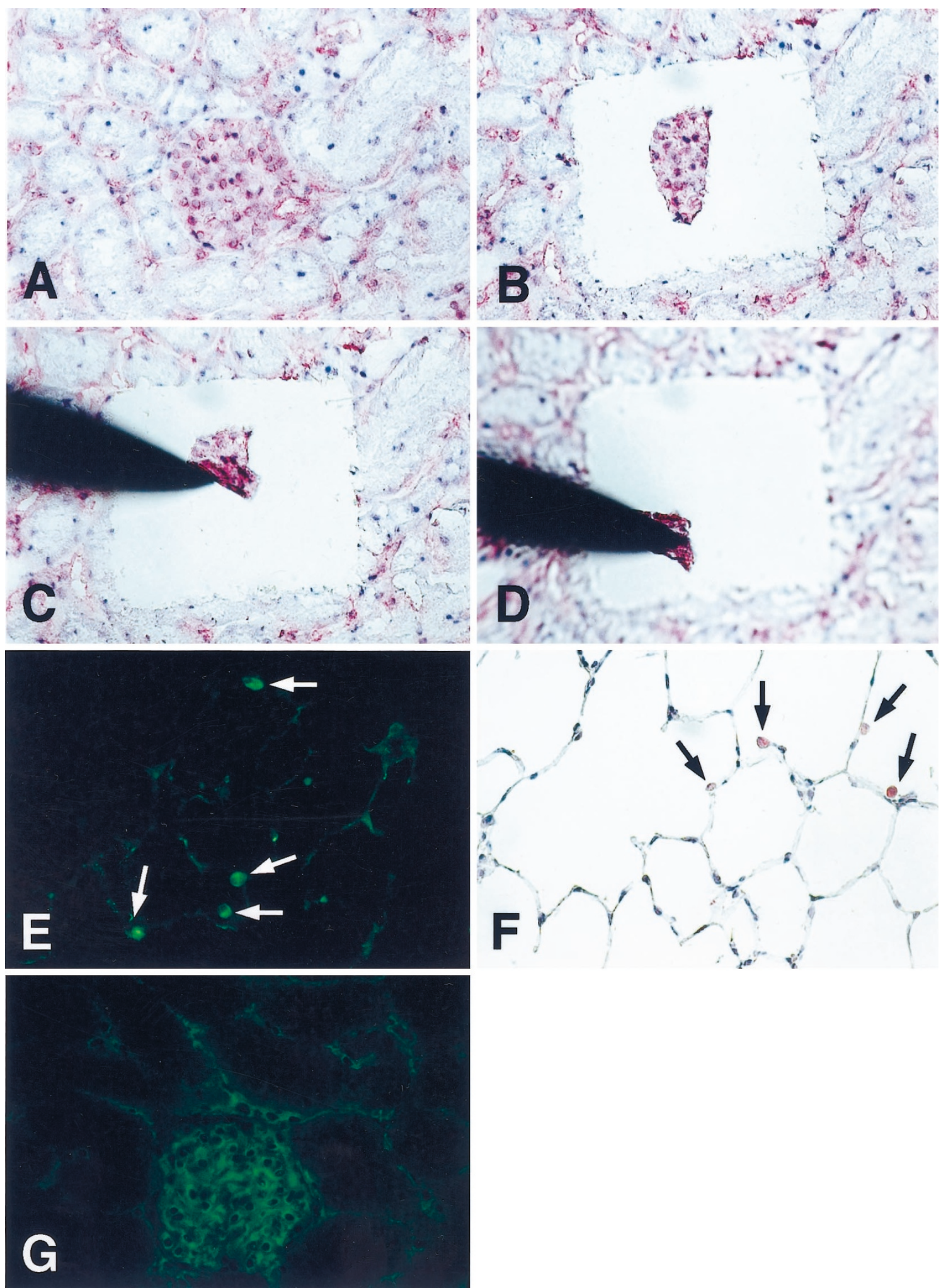

\section{Figure 1.}

A to $D$, Laser-assisted cell picking in frozen tissue after immunohistochemical staining. Kidney, stained with the RECA-1 antibody (rat pan-endothelial), alkaline phosphatase and monoclonal anti-alkaline phosphatase (APAAP). A, A glomerulum is selected. B, Removal of the adjacent tissue by the UV-laser and reduction of the stained glomerulus to obtain a cell cluster with approximately 20 nuclei. C, The cell cluster is harvested with a needle. D, The cell cluster adheres tightly to the needle and is lifted. E to G, Rapid immunostaining; examples of APAAP immunohistochemical and FITC indirect immunofluorescence staining with rapid protocol. Cryosections of lung and kidney are shown before laser microdissection of alveolar or glomerular cells. Original magnifications $\times 40$. E, Rapid immunofluorescence staining of the lung with the ED1 (rat macrophage/monocyte) antibody. Arrows show the specifically stained alveolar macrophages. F, Rapid immunohistochemical staining of the lung with the ED1 (rat macrophage/monocyte) antibody. G, Rapid immunofluorescence staining of the kidney with the RECA-1 (rat pan-endothelial) antibody. Clear identification of RECA-1 positive cells. 
$\begin{array}{lllllllllllllllll}1 & 2 & 3 & 4 & 5 & 6 & 7 & 8 & 9 & 10 & 11 & 12 & 13 & 14 & 15 & 16 & 17\end{array}$

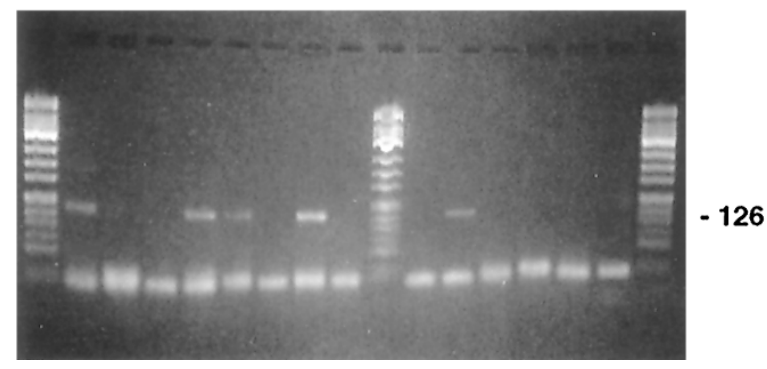

Figure 2

Typical example of RT-PCR analysis for PBGD mRNA after laser-assisted cell picking. Immunofluorescence staining was done with tissue sections from a formalin-fixed lung. Oligocellular clusters with approximately 20 nuclei per sample were isolated. Eight samples (lanes 2 to 9) were digested with proteinase K, 5 samples (lanes 11 to 15) were not. Intron spanning primers were used for amplification. PBGD RT-PCR product with 126 bp length was generated. Band intensity varied slightly, but was not related to any of the factors investigated. Lane 16, sample without RT; lanes 1, 10, and 17, ФX174 Hinfl. 2.5\% agarose gel/TBE gel stained with ethidium bromide.

immediately processed further. Similar data were reported by Goldsworthy et al (1999). However, the additional decline in RNA recovery upon subsequent storage in staining buffer was markedly reduced. This finding suggests suppression of endogenous RNases due to mild formalin fixation or "capturing" of RNA within the tissue matrix by cross-linking.

Effect of Antibodies and Staining Reagents. Comparing the results of pure buffer storage to the data of APAAP immunohistochemistry and FITC indirect immunofluorescence, it is obvious that there is an additional effect of applied antibodies as well as staining reagents. These findings are confirmed by the investigation of cRNA aliquots undergoing incubation with antibodies and developing solution. This might be due to (a) RNases that are attached to the antibodies and (b) to the alkaline $\mathrm{pH}$ (9.0) during the enzymatic reaction. Even an unspecific RNase activity of antibody epitopes is conceivable. Although Fend et al (1999) recommended the application of an RNase inhibitor to reduce the loss of RNA, we, however, could not find any significancy for an advantageous use within picked samples from stained sections. This finding was confirmed by the results of cRNA investigation.

Proteinase K Digestion Step. As recently depicted (Fink et al, 1999), mRNA detection from hematoxilin stained cryosections was most effective if an RNA extraction step, DNase digestion (if possible), PK digestion, and nested PCR were omitted. Thus, additional loss of the already limited amount of RNA could be avoided, the processing simplified, and contaminations and preparation time reduced. When formalin fixation turned out to be advantageous for immunostaining, higher efficiency rates were consistently obtained by introducing a mild PK treatment. Subsequent denaturation of the proteinase served simultaneously for denaturation of the RNA before reverse transcription. The positive effect of digestion was also seen by Krafft et al (1997) investigating extracted RNA from routinely formalin-fixed and paraffin-embedded tissue. Within our samples, the effect was obvious for buffer-stored and immunostained cryosections, but was particularly impressive for formalin-fixed tissue-whether lung or kidneyundergoing immunostaining or immunofluorescence procedures.

To reduce the number of antibodies and incubation periods, we introduced immunofluorescence staining. The combination of formalin fixation, mild PK digestion, and rapid immunofluorescence detection indeed obtained highest efficiency of mRNA amplification both in lung (46\% and $49 \%)$ and kidney (58\%) tissue. This increase in RNA recovery clearly outweighs the loss of comfort due to the switch from fluorescence to brightfield microscopy during the picking procedure.

In conclusion, mRNA amplification from oligocellular clusters or a few cell profiles obtained by laserassisted cell picking can be combined with immunodetection of specific cell types. To minimize loss of RNA recovery, formalin fixation of the tissue, the most possible reduction of incubation times, and a mild digestion with PK is suggested. In consequence, best results were obtained by rapid immunofluorescence techniques.

\section{Materials and Methods}

\section{Tissue Preparation and Fixation}

Cryopreparation. Lungs from male Sprague Dawley rats were dissected as described previously (Ermert et al, 1998). After short perfusion, 6 ml TissueTek (Sacura Finetek, Torrance, California) was instilled into the airways via the trachea. Finally, the lungs were snap frozen in liquid nitrogen and stored at $-80^{\circ} \mathrm{C}$. Kidneys were prepared, immediately snap frozen in liquid nitrogen, and embedded in TissueTek (Sacura Finetek) for sectioning.

Formalin Fixation by Perfusion. Isolated rat lungs were prepared and briefly perfused with KrebsHenseleit (KH) buffer as described (Ermert et al, 1998). Next, perfusion with $4.5 \%$ formaldehyde solution (Roti-Histofix, Roth, Germany) was undertaken for 15 minutes, followed by a rinsing procedure with $\mathrm{KH}$ buffer to remove the residual formalin. Finally, TissueTek (Sacura Finetek) was instilled into the airways and the lungs were treated as described in "Cryopreparation."

Formalin Fixation by Immersion. Lungs and kidneys were dissected and stored in $4.5 \%$ formaldehyde solution for 2 to 6 hours. The organs were then snap frozen in liquid nitrogen and stored at $-80^{\circ} \mathrm{C}$.

\section{Immunostaining}

Immunohistochemistry. Immunohistochemistry was performed by the APAAP technique, slightly modified from Cordell et al (1984). Depending on the kind of tissue, 6- to 9- $\mu \mathrm{m}$ thick cryostat sections (3 minutes ice-cold acetone fixed) were incubated for 3 to 10 minutes with the murine primary monoclonal antibodies ED1 (rat macrophage/monocyte antibody; 1:25; Serotec, Germany) and RECA-1 (rat panendothelial 
A

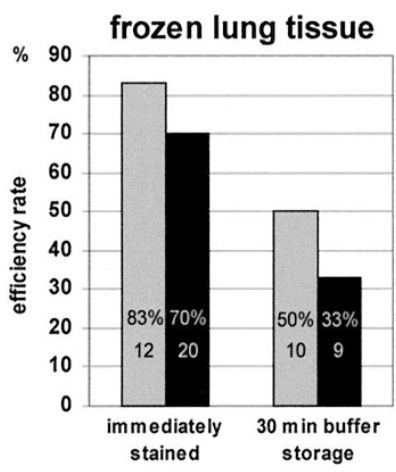

formalin fixed lung tissue

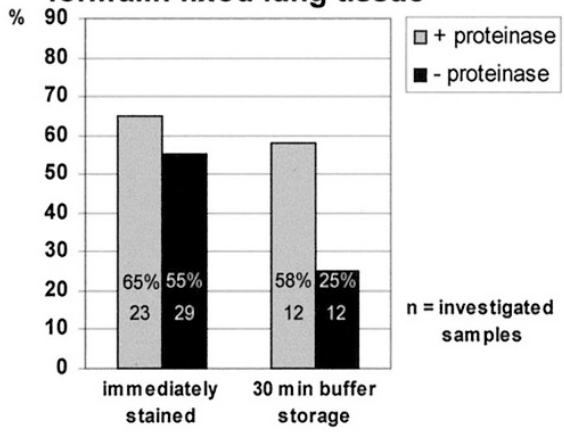

B
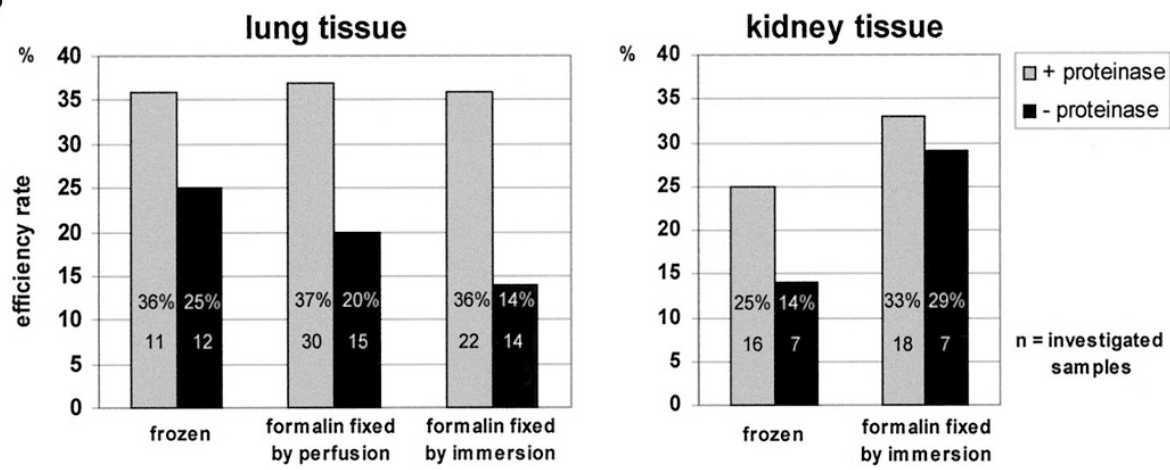

C
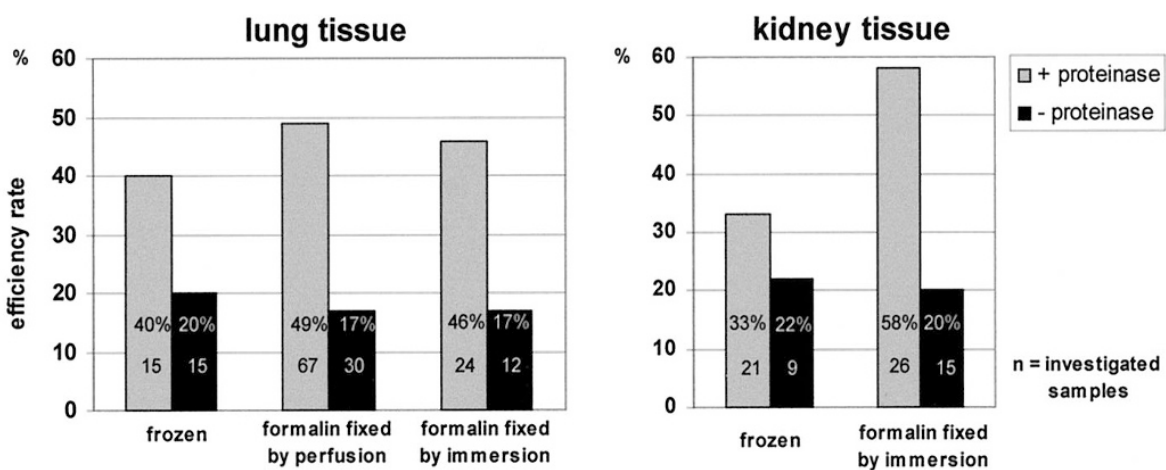

Figure 3.

A, Effect of a 30-minute incubation period on the efficiency rate of mRNA amplification in the absence and presence of PK digestion. Glass slides with mounted tissue slices were immediately stained with Hemalaun before cell picking. Alternatively, they were stored in a staining jar containing $30 \mathrm{ml}$ sterile Tris-buffered saline ( $\mathrm{pH}$ 7.5) for 30 minutes and afterward stained. Per sample, a cell cluster containing approximately 20 nuclei was picked. The efficiency rate gives the percentage of samples in which PBGD mRNA amplification is detected. For the different approaches, total numbers of investigated samples are additionally given. B, Effect of APAAP immunohistochemical staining on the efficiency rate of mRNA amplification in the absence and presence of PK digestion. Alternatively, frozen and formalin-fixed tissue were used. Sections from lung and kidney tissue were stained using a short-time APAAP protocol (25 to 40 minutes). Per sample, a cell cluster containing approximately 20 nuclei was picked for RT-PCR. The efficiency rate gives the percentage of samples in which PBGD mRNA amplification is detected. Total numbers of investigated samples are also given. C, Effect of indirect immunofluorescence labeling (FITC) on the efficiency rate of mRNA amplification in the absence and presence of PK digestion. Alternatively, frozen and formalin-fixed tissue were used. Sections from lung and kidney tissue were stained using a short-time immunofluorescence protocol (10 to 20 minutes). Per sample, a cell cluster containing approximately 20 nuclei was picked for RT-PCR. The efficiency rate gives the percentage of samples in which PBGD mRNA amplification is detected. Total numbers of investigated samples are also given.

antibody; 1:25; Serotec via Biozol Diagnostika, Eching, Germany) at room temperature, followed by 3 to 10 minutes incubation at room temperature with rabbit anti-mouse immunoglobulin (rabbit-“link," 1:40; Dako Diagnostika, Hamburg, Germany) supplemented with pooled rat serum (1:750; Sigma Chemie, Deisenhofen, Germany) to inhibit nonspecific cross-reactivity, and mouse-APAAP-complex (1:50; Dako), respectively. All antibodies were diluted in Tris-buffered saline ( $\mathrm{pH} 7.5)$. Samples were washed twice in sterile buffer (Trisbuffered saline; pH 7.5) between "link" and APAAP steps. Alkaline phosphatase substrate reaction was performed at $\mathrm{pH}$ 9.0, either with new fuchsin (100 $\mu \mathrm{g} / \mathrm{ml})$ and levamisole $(400 \mu \mathrm{g} / \mathrm{ml})$ or New Fuchsin Substrate System (Dako) for 10 to 15 minutes at room temperature. Finally, sections were counterstained 


\begin{tabular}{|c|c|c|c|c|c|}
\hline & $\begin{array}{l}\text { (A) RNA } \\
\text { extraction only } \\
\text { (reference) }\end{array}$ & $\begin{array}{c}\text { (B) Ab } 30 \text { min; } \\
- \text { RNase } \\
\text { inhib. }\end{array}$ & $\begin{array}{c}\text { (C) Ab } 30 \text { min; } \\
+ \text { RNase } \\
\text { inhib. }\end{array}$ & $\begin{array}{l}\text { (D) Ab } 30 \text { min; } \\
\text { Staining } \\
\text { solution } 30 \\
\text { min; - RNase } \\
\text { inhib. }\end{array}$ & $\begin{array}{l}\text { (E) Ab } 30 \text { min; } \\
\text { Staining } \\
\text { solution } 30 \\
\text { min; + RNase } \\
\text { inhib. }\end{array}$ \\
\hline $\begin{array}{l}\text { Relative CRNA amount } \\
\qquad\left(1.9^{\Delta \mathrm{CT}} \pm \mathrm{SEM}\right)\end{array}$ & 1 & $0.48 \pm 0.16$ & $0.51 \pm 0.14$ & $0.27 \pm 0.10$ & $0.25 \pm 0.08$ \\
\hline
\end{tabular}

Based on following equation, we used comparative quantitation $\left(\Delta C_{T}\right.$ method) normalizing cRNA amounts undergoing the selected conditions to cRNA without treatment (all cRNA aliquots were extracted in parallel):

$$
\frac{\mathrm{S}_{0}}{\mathrm{R}_{0}}=\mathrm{K} \cdot(1+\mathrm{E})^{(\mathrm{CT}, \mathrm{T}-\mathrm{CT}, \mathrm{S})}
$$

where: $\mathrm{S}_{0}$, initial number of sample cRNA copies; $\mathrm{R}_{0}$, initial number of reference cRNA copies; $\mathrm{E}$, efficiency of amplification; CT,S, threshold cycle of sample cRNA; $\mathrm{CT}, \mathrm{R}$, threshold cycle of reference cRNA; K, constant.

In pilot experiments we showed that amplification efficiency of PBGD amounted to $0.9 \pm 0.02(=90 \% \pm 2 \%)$. K is assumed to be equal within a definite fluorogenic-labeled primer/probe system and thus does not influence the comparison of calculated relative ratios. In total, 8 experiments with the given parameters were performed; mean \pm standard error of mean (SEM) are shown. Statistical significance was calculated using the Mann-Whitney test $(A$ vs $(B+C+D+E): p<$ $0.001 ; A$ vs $(B+C): p=0.01 ; A$ vs $(D+E): p<0.001)$ and the Wilcoxon test $((B+C)$ vs $(D+E): p=0.04)$. Ab, antibody.

with hematoxilin for 45 seconds, followed by alcohol immersion and stored in $100 \%$ ethanol until picking that followed within less than 30 minutes.

Immunofluorescence. Preparation of sections was performed identically to that described for immunohistochemistry. Primary antibody was incubated for 3 to 10 minutes at room temperature, and after washing with buffer, incubation with the FITC-conjugated goat anti-mouse immunoglobulin (1:100; Organon Teknika, Durham, North Carolina) was performed for 3 to 10 minutes at room temperature. Finally, sections were washed, immersed in ethanol, and stored in 100\% ethanol until picking. For negative control, the first antibody was replaced by MR12/53 (mouse-antirabbit immunoglobulin; $1.0 \mu \mathrm{g} / \mathrm{ml}$; Dako).

\section{Cell picking and RT-PCR}

Cell picking was performed as described in detail recently (Fink et al, 1999). The UV-laser Robot Microbeam (P.A.L.M., Mikrolaser Technologie, Bernried, Germany) consists of a pulsed, low-energy $337 \mathrm{~nm}$ nitrogen laser and an inverted microscope (Axiovert 135; Carl Zeiss, Jena, Germany). It is equipped with a motorized, computer-controlled microscope stage and micromanipulator. Laser cutting is conveniently moved by the computer mouse. Cell clusters or single cell profiles of interest are selected and lasermicrodissected under visual control (Fig. 1, A to D). They are harvested by a syringe needle and transferred into a reaction tube containing $10 \mu \mathrm{l}$ firststrand-buffer. In each sample, oligocellular clusters containing approximately 20 cell profiles and nuclei each were picked.

For immunofluorescence a mercury vapor lamp is coupled to the epifluorescence illumination path. After immunofluorescence staining, cells of interest are selected using fluorescence microscopy. To find special structures within the tissue slice again, it is possible to store exactly the position of the stage. The laser beam can be moved around the selected cell cluster. After- ward, brightfield illumination is switched on. The clusters can be harvested, as the structure of these selected clusters or cell profiles can also be identified under brightfield microscopy with a nearly closed condenser.

Within lung tissue, alveolar cells (alveolar septum cells and macrophages) were picked, within kidney tissue, glomerulus cells were harvested. Samples with isolated cells were frozen in liquid nitrogen. Depending on the extent of laser application, the picking procedure lasted 3 to 6 minutes per sample. After short thawing, PK ( $1 \mu \mathrm{l} ; 1 \mathrm{mg} / \mathrm{ml}$; Sigma) was added and the samples were incubated for 30 minutes at $53^{\circ} \mathrm{C}$. Afterward PK as well as RNA were denaturated at $99^{\circ} \mathrm{C}$ for 7 minutes, followed by storage on ice for 5 minutes. RT master mix contained $2 \mu \mathrm{lgCl}_{2}$ (25 mM), $2 \mu$ l GeneAmp 10× PCR Buffer II (100 mm Tris-HCl, $\mathrm{pH}$ 8.3, $500 \mathrm{~mm} \mathrm{KCl}), 1 \mu \mathrm{l}$ dNTP (10 mм each), $1 \mu \mathrm{l}$ random hexamers $(50 \mu \mathrm{M}), 0.5 \mu \mathrm{l}$ RNase inhibitor (10 $\mathrm{U})$, and $1 \mu \mathrm{l} \mathrm{MuLV}$ reverse transcriptase (50 U). Except for dNTP (Eurobio, Raunheim, Germany), all reagents were purchased from PE Applied Biosystems (Weiterstadt, Germany). Samples were incubated at $20^{\circ} \mathrm{C}$ for 10 minutes and at $43^{\circ} \mathrm{C}$ for 60 minutes. The reaction was stopped by heating to $99^{\circ} \mathrm{C}$ for 5 minutes. Conventional PCR for PBGD standard gene was performed applying $8 \mu \mathrm{l}$ cDNA of each picked sample to the master mix (Fink et al, 1999). PCR conditions were modified to $95^{\circ} \mathrm{C}$ for 6 minutes, followed by 55 cycles with $95^{\circ} \mathrm{C}$ for 20 seconds, $62^{\circ} \mathrm{C}$ for 20 seconds, and $72^{\circ} \mathrm{C}$ for 30 seconds.

Cloning and cRNA Synthesis of a PBGD-PCR Product. A PBGD cDNA fragment was synthesized by RT-PCR with PBGD-specific primers containing an Xhol site at the $5^{\prime}$ end and a Hindlll site at the $3^{\prime}$ end. After restriction enzyme digest of the purified fragment by Hindlll and Xhol, it was ligated into the Xhol and HindIII polylinker sites of the pcDNA3 plasmid (InVitrogen, San Diego, California). The Hindlll linearized plasmid served as template for PBGD cRNA transcription using the SP6 polymerase-promoter system. 
PBGD cRNA was purified by anion exchange column (Qiagen, Hilden, Germany) and its concentration was spectrophotometrically determined.

cRNA Extraction. For RNA extraction, $800 \mu$ l RNAzol B (WAK-Chemie Medical, Bad Homburg, Germany) was added to the RNA aliquots and isolation steps were performed according to the manufacturer's protocol. Finally, a 75\%-ethanol-washed RNA pellet was air-dried and dissolved in $20 \mu \mathrm{l}$ DEPCtreated $\mathrm{H}_{2} \mathrm{O}$, and $10 \mu \mathrm{l}$ was reverse transcribed (see above).

Real-Time PCR and Relative cRNA Quantitation. Relative cRNA quantitation was performed by the Sequence Detection System 7700 (PE Applied Biosystems) and real-time PCR as recently described in detail (Fink et al, 1998). Two microliters of cDNA per sample was added to the master mix. Cycling conditions were modified to $95^{\circ} \mathrm{C}$ for 10 minutes, followed by 40 cycles of $95^{\circ} \mathrm{C}$ for 15 seconds, and $61^{\circ} \mathrm{C}$ for 60 seconds. Calculation of cRNA ratios is given in Table 2.

Statistical Analysis. Picked sample results were obtained on a matched pair basis. In total, 10 lungs (4 cryo, 2 formalin-perfused, 2 formalin-immersed, and 2 divided for cryo/formalin immersion) and 5 kidneys (2 cryo, 2 formalin-immersed, and 1 divided for cryo/ formalin immersion) of different rats were investigated. In several sessions, 6 to 14 samples each were picked from adjacent sections of the respective tissue after undergoing the respective treatment (ie staining). The samples were then randomly divided for PK digestion or non-digestion. Statistical significance was calculated by Pearson's $\chi^{2}$ test. cRNA experiments were analyzed by Mann-Whitney test and Wilcoxon test.

\section{Acknowledgements}

We thank E. Kuhlmann-Farahat and $H$. Wallenfels for skillful technical assistance.

\section{References}

Becker I, Becker KF, Röhrl MH, and Höfler H (1997). Laserassisted preparation of single cells from stained histological slides for gene analysis. Histochem Cell Biol 108:448-451.

Cordell JL, Falini B, Erber WN, Gosh AK, Abdulaziz Z, MacDonald S, Pulford KAF, Stein H, and Mason DY (1984). Immunoenzymatic labelling of monoclonal antibodies using immune complexes of alkaline phosphatase and monoclonal anti-alkaline phosphatase (APAAP complexes). J Histochem Cytochem 32:219-229.

d'Amore F, Stribley JA, Ohno T, Wu G, Wickert RS, Delabie J, Hinrichs SH, and Chan WC (1997). Molecular studies on single cells harvested by microdissection from archival tissue sections previously stained by immunohistochemistry or nonisotopic in situ hybridization. Lab Invest 76:219-224.

Emmert-Buck MR, Bonner RF, Smith PD, Chuaqui RF, Zhuang Z, Goldstein SR, Weiss R, and Liotta LA (1997). Laser capture microdissection. Science 274:998-1001.
Ermert L, Ermert M, Althoff A, Merkle M, Grimminger F, and Seeger W (1998). Vasoregulatory prostanoid generation proceeds via cyclo-oxygenase-2 in non-inflamed rat lungs. J Pharmacol Exp Therap 286:1309-1314.

Fend F, Emmert-Buck M, Chuaqui R, Cole K, Lee J, Liotta LA, and Raffeld M (1999). Immuno-LCM: Laser capture microdissection of immunostained frozen sections for mRNA analysis. Am J Pathol 154:61-66.

Fink L, Seeger W, Ermert L, Hänze J, Stahl U, Grimminger F, Kummer W, and Bohle RM (1998). Real-time quantitative RT-PCR after laser-assisted cell picking. Nature Medicine 4:1329-1333.

Fink L, Stahl U, Ermert L, Kummer W, Seeger W, and Bohle RM (1999). Rat porphobilinogen deaminase: a pseudogenefree internal standard for laser-assisted cell picking. BioTechniques 26:510-516.

Goldsworthy SM, Stockton PS, Trempus CS, Foley JF, and Maronpot RR (1999). Effects of fixation on RNA extraction and amplification from laser capture microdissected tissue. Mol Carcinog 25:86-91.

Hiller T, Snell L, and Watson PH (1996). Microdissection RT-PCR analysis of gene expression in pathologically defined frozen tissue sections. BioTechniques 21:38-44.

Ho M, To MD, Done SJ, Redston M, and Andrulis IL (1998). Analysis of mRNA from microdissected frozen tissue sections without RNA isolation. Am J Pathol 153:47-51.

Hölschermann $H$, Bohle RM, Zeller $H$, Schmidt $H$, Stahl $U$, Fink L, Grimm H, Tillmanns H, and Haberbosch W (1999). In situ detection of tissue factor within coronary intima in rat cardiac allograft vasculopathy. Am J Pathol 154:211-220.

Jin L, Thompson CA, Qian X, Kuecker SJ, Kulig E, and Lloyd RV (1999). Analysis of anterior pituitary hormone mRNA expression in immunophenotypically characterized single cells after laser capture microdissection. Lab Invest 79:511512.

Krafft AE, Duncan BW, Bijwaard KE, Taubenberger JK, and Lichy JH (1997). Optimization of the isolation and amplification of RNA from formalin-fixed, paraffin-embedded tissue: the armed forces institute of pathology experience and literature review. Mol Diagn 2:217-230.

Küppers R, Zhao M, Hansmann ML, and Rajewsky K (1993). Tracing $B$ cell development in human germinal centres by molecular analysis of single cells picked from histological sections. EMBO J 12:4955-4967.

Kummer W, Fink L, Dvorakova M, Haberberger R, and Bohle RM (1998). Rat cardiac neurons express the non-coding R-exon (exon 1) of the cholinergic gene locus. NeuroReport 9:2209-2212.

Schütze K and Lahr G (1998). Identification of expressed genes by laser-mediated manipulation of single cells. Nature Biotech 16:737-742. 